\title{
EBSD INVESTIGATION AND MODELING OF THE MICROSTRUCTURAL EVOLUTIONS OF SUPERALLOY 718 DURING HOT DEFORMATION
}

\author{
Jean-Philippe Thomas ${ }^{1,2}$, Etienne Bauchet ${ }^{1}$, Christian Dumont ${ }^{2}$, Frank Montheillet ${ }^{1}$ \\ ${ }^{1}$ Ecole Nationale Supérieure des Mines, Centre SMS, CNRS UMR 5146; 158 cours Fauriel; 42023 Saint-Etienne Cedex 2, France \\ ${ }^{2}$ Aubert\&Duval Alliages; BP1; 63770 Les Ancizes Cedex, France
}

Keywords: Alloy 718, Dynamic Recrystallization, Hot Working, Nucleation, Disorientation, Subboundary

\begin{abstract}
Hot deformation tests of superalloy 718 were carried out both in torsion and uniaxial compression in order to investigate the microstructural evolutions of this alloy. Post-deformation holding times were also performed. The obtained dynamic and metadynamic - most often partially - recrystallized microstructures were characterized using the EBSD technique. Particular attention was paid to the local crystallographic rotation of specific subgrains as it leads to the nucleation of most of the first new grains. Twin boundary generation, and consecutive disorientation, for producing the second and further generations of recrystallized grains, were also studied. Thanks to these data, an empirical model, based on Avrami formulation, was developed. Furthermore, as $\delta$ phase $\left(\mathrm{Ni}_{3} \mathrm{Nb}\right)$ precipitation can modify significantly the recrystallization and subsequent grain growth kinetics of alloy 718, a mechanism-based model was designed to take into account the coupling effects of recrystallization and $\delta$ phase precipitation.
\end{abstract}

\section{Introduction}

Mechanical properties of superalloy 718 strongly depend on its microstructure. Every step of the thermomechanical processing of discs and other rotating parts of turbine has to be well controlled. In that way, accurate knowledge and modeling of microstructural evolutions of alloy 718 are necessary to optimize the process parameters. Investigation and modeling of these evolutions were therefore carried out.

In this paper, we will first describe experiments, and present experimental results. Emphasis will be put on the typical sequence and main mechanisms of the microstructural evolutions of alloy 718. In a second part, empirical modeling aspects will be dealt with. Thirdly, the main characteristics and solving steps of a mechanism-based model will be presented. And finally, we will put the focus on the coupling of such models with finite element calculations, to end with an example of industrial application.

\section{Experimental technique and results}

\section{Experiment description}

To meet the numerous applications of this alloy, several alternate chemical compositions of alloy 718 exist. The element whose content varies the most and with the greatest effects - because of $\delta$ phase $\left(\mathrm{Ni}_{3} \mathrm{Nb}\right)$ precipitation - is niobium. Thus two extreme niobium contents were chosen. One is called "high niobium" with $5.4 \mathrm{wt} \%$ niobium, and the other one is named "low niobium" with $5.0 \mathrm{wt} \%$ niobium. Detailed compositions are shown in Tables I and II.
Table I. Chemical composition of "high niobium" tested 718 (weight percent)

\begin{tabular}{|c|c|c|c|c|c|c|c|}
\hline $\mathrm{C}$ & $\mathrm{Mn}$ & $\mathrm{Si}$ & $\mathrm{Cr}$ & $\mathrm{Ni}$ & $\mathrm{Co}$ & $\mathrm{Fe}$ & $\mathrm{Mo}$ \\
0.024 & 0.06 & 0.08 & 17.89 & $\mathrm{Bal}$. & 0.18 & 17.35 & 2.97 \\
\hline $\mathrm{Nb}$ & $\mathrm{Ti}$ & $\mathrm{Al}$ & $\mathrm{B}$ & $\mathrm{S}$ & $\mathrm{Cu}$ & $\mathrm{Ta}$ & $\mathrm{P}$ \\
5.4 & 1.07 & 0.46 & $2.8 \mathrm{e}-3$ & $2 \mathrm{e}-4$ & 0.03 & 0.01 & 0.007 \\
\hline
\end{tabular}

Table II. Chemical composition of "low niobium" tested 718 (weight percent)

\begin{tabular}{|c|c|c|c|c|c|c|c|}
\hline $\mathrm{C}$ & $\mathrm{Mn}$ & $\mathrm{Si}$ & $\mathrm{Cr}$ & $\mathrm{Ni}$ & $\mathrm{Co}$ & $\mathrm{Fe}$ & $\mathrm{Mo}$ \\
0.011 & 0.055 & 0.01 & 17.93 & $\mathrm{Bal}$. & 0.24 & 18.57 & 3.0 \\
\hline $\mathrm{Nb}$ & $\mathrm{Ti}$ & $\mathrm{Al}$ & $\mathrm{B}$ & $\mathrm{S}$ & $\mathrm{Cu}$ & $\mathrm{V}$ & $\mathrm{P}$ \\
4.98 & 1.08 & 0.515 & $3.8 \mathrm{e}-3$ & $<1 \mathrm{e}-4$ & 0.015 & 0.023 & 0.002 \\
\hline
\end{tabular}

To cover the large domain of parameter combinations practiced in industrial processes, wide ranges of temperature $\left(900^{\circ} \mathrm{C}\right.$ to $\left.1120^{\circ} \mathrm{C}\right)$ and strain rate $\left(0.001 \mathrm{~s}^{-1}\right.$ to $\left.10 \mathrm{~s}^{-1}\right)$ were tested with strains up to 3 . The effect of post-deformation holding times (1 second to 1 hour) was also studied. Several initial grain sizes were chosen from $35 \mu \mathrm{m}$ to $200 \mu \mathrm{m}$, combined with various states of $\delta$ phase $\left(\mathrm{Ni}_{3} \mathrm{Nb}\right)$ precipitation. Depending on pre-thermal treatments, the $\delta$ phase distribution ranged from no precipitates, to globular precipitates, to even acicular $\delta$ phase. Sampling locations in intermediate product forms were selected from center to periphery to study the effect of the amplitude of niobium segregation due to initial ingot solidification.

These samples were deformed in both uniaxial compression and torsion. Uniaxial compression specimens diameter was $10 \mathrm{~mm}$ for $15 \mathrm{~mm}$ height and they were lubricated with boron nitride. Torsion specimens deformed zone had a $3 \mathrm{~mm}$ radius for a $27 \mathrm{~mm}$ length. Uniaxial compression was used so that data was acquired with a deformation path as close as possible to the industrial ones. But this kind of test does not allow testing strains larger than 1.0 with good accuracy. In addition, minimum quench time is at least of 2 seconds, whereas at high strain rates, quench time becomes a critical parameter because of rapid metadynamic evolution. Thus torsion tests were performed, even though single shear is less appropriate to represent industrial deformation path. Torsion was useful to reach strains up to 3 . In addition, for strain rates up to $10 \mathrm{~s}^{-1}$, short quench time were achieved through use of a $3^{\circ} \mathrm{C}$ helium flow projected on the deformed zone, while the sample was still inside the furnace, approximately $1 / 10^{\text {th }}$ of a second after test end. Duplicate tests under uniaxial compression and torsion loading enabled comparison of the two deformation processes.

Specimens were characterized using the EBSD technique for an accurate determination of microstructural parameters and for a better understanding of the mechanisms involved in alloy 718 microstructural evolutions. Uniaxial compression samples were observed at their center, where strain was assumed to be about 
$10 \%$ higher than expected because of friction. The observation zone for torsional samples was located tangentially to cylinder surface, where the nominal strain is reached. But as polishing resulted in a slightly smaller radius than $3 \mathrm{~mm}$, the actual observed strain was assumed to be about $95 \%$ of the nominal one.

\section{$\underline{\text { Experimental results }}$}

Flow stress. The usual dependence of flow stress with temperature and strain rate was observed, revealing that thermally activated mechanisms govern the hot working behavior of alloy 718. Up to strains of about 0.3 , strain hardening occurs, due to energy storage. Softening follows, indicating the beginning of microstructural changes.
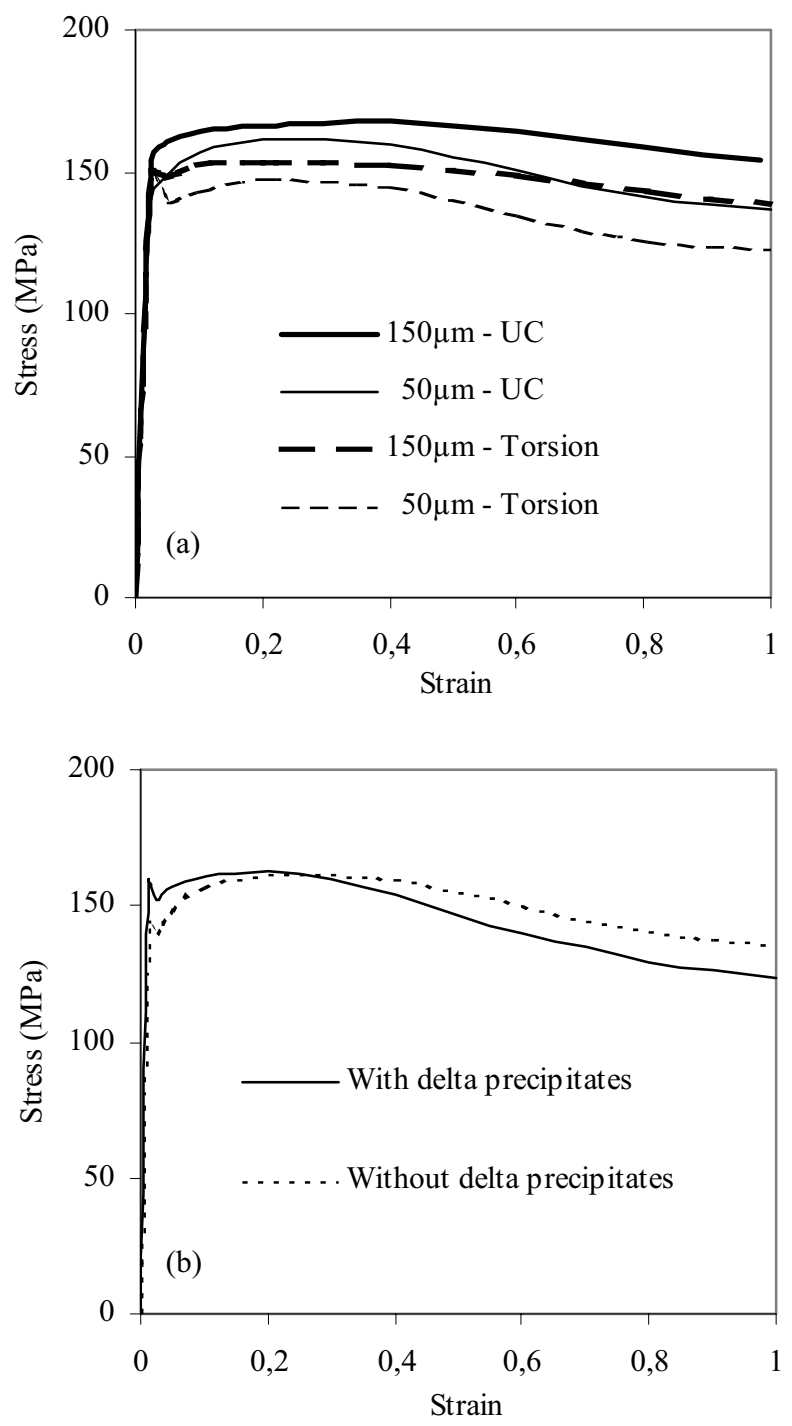

Figure 1. Stress-strain curves of alloy 718 deformed at $1000^{\circ} \mathrm{C}$ $0.01 \mathrm{~s}^{-1}$, (a) for initial grain sizes of $150 \mu \mathrm{m}$ and $50 \mu \mathrm{m}$, in torsion and uniaxial compression, and

(b) for an initial grain size of $50 \mu \mathrm{m}$ with and without initial $\delta$ phase precipitates, in uniaxial compression
Material tends to soften later and with less efficiency for coarser initial microstructures, as dynamic recrystallization is commonly known to be more sluggish for large initial grains (Fig.1a). On the contrary, softening seems to be more rapid for microstructures with initial $\delta$ phase precipitates than for the solution treated ones, showing that these precipitates do not slow down dynamic recrystallization (Fig.1b).

Microstructural evolutions of alloy 718 during hot working. Characterization by EBSD of deformed microstructures reveals the typical topology of partially recrystallized microstructures, in which initial grains are surrounded by necklaces of recrystallized grains necklaces (Fig.2). Such topology leads to suppose that the recrystallization mechanisms of alloy 718 belong to the category of discontinuous (or classical) dynamic recrystallization. This type of recrystallization has been widely described elsewhere [1]. It is based on a sequence of strain hardening - energy storage - which leads to the nucleation of new grains on the initial grain boundaries.

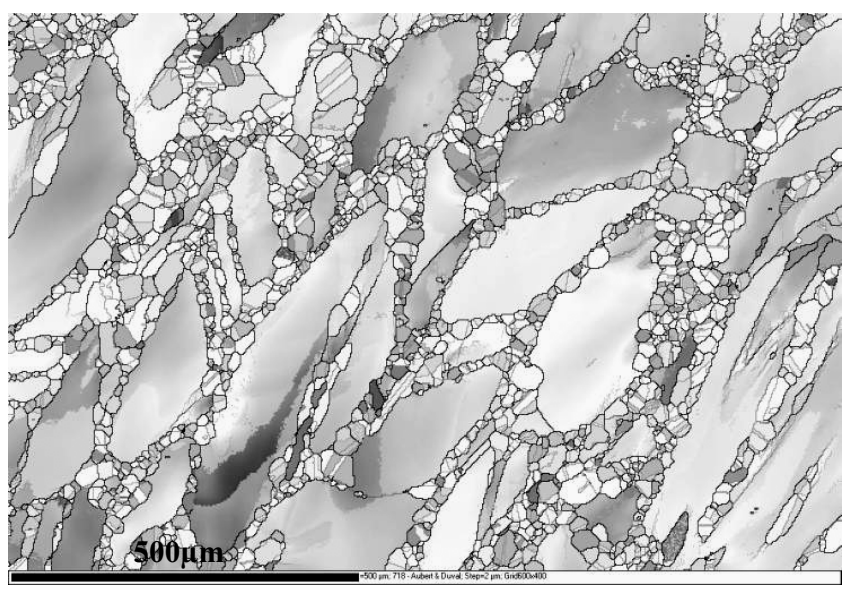

Figure 2. EBSD Map

$\mathrm{D}_{\mathrm{o}}=200 \mu \mathrm{m}-980^{\circ} \mathrm{C} 1 \mathrm{~s}^{-1} \varepsilon=0.7+140 \mathrm{~s}-$ Torsion

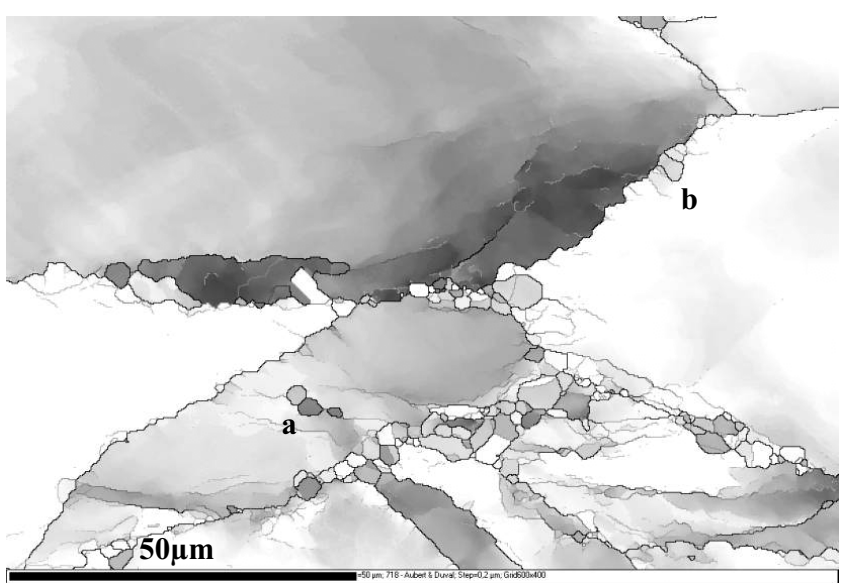

Figure 3. FEG EBSD Map

$\mathrm{D}_{\mathrm{o}}=50 \mu \mathrm{m}-980^{\circ} \mathrm{C} 0.01 \mathrm{~s}^{-1} \varepsilon=0.4-$ Uniaxial compression Boundaries in light gray $\left(2^{\circ}\right)$ to black $\left(\geq 15^{\circ}\right)$ $\mathrm{a}:$ nuclei that appeared inside an initial grain $\mathrm{b}$ : nucleus formed by the bulging of an initial grain boundary 
However, by focusing on the recrystallized grain nuclei of alloy 718 reveals that they appear not only on initial grain boundaries but also inside strained grains (Fig.3-a). This is impossible for discontinuous dynamic recrystallization, as it needs an initial grain boundary to bulge for the generation of new nuclei (Fig.3b). Another mechanism of nucleation, which seems to be responsible for the nucleation of at least $90 \%$ of new grains, is therefore involved.

These observations lead to believe that a recrystallization form called continuous recrystallization [2] occurs, but in a more localized way than the usual one. It was first observed in aluminum alloys and is based on a recrystallization sequence using high levels of restoration, allowed by the high stacking fault energy of these alloys, to store geometrically necessary (GN) dislocations in subboundaries, disorient them progressively, and make continuously appear new high angle mobile boundaries from subboundaries. In aluminum alloys, this phenomenon occurs widely in the whole grain. However, for alloy 718, they affect more local regions because the stacking fault energy does not seem to be high enough to allow an efficient recovery.

The disorientation of alloy 718 subboundaries is mainly due to strain incompatibilities between neighbor grains subjected to an imposed deformation tensor. Strain incompatibility induces heterogeneity in the form of variations of local crystallographic orientations in grains: GN dislocations accommodate these variations. As strain increases, GN dislocations rearrange themselves into subboundaries that cross initial grains and progressively divide them into several finer grains, as illustrated in figure 4.

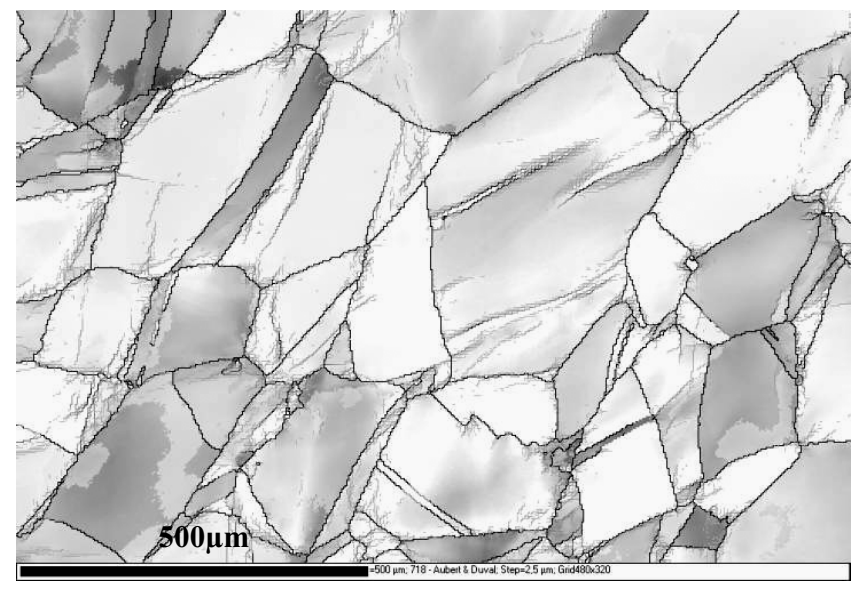

Figure 4. EBSD Map

$\mathrm{D}_{\mathrm{o}}=200 \mu \mathrm{m}-900^{\circ} \mathrm{C} 0.001 \mathrm{~s}^{-1} \varepsilon=0.4-$ Torsion

Boundaries in light gray $\left(2^{\circ}\right)$ to black $\left(\geq 15^{\circ}\right)$

Continuing deformation increases the effect of these heterogeneity and disorientation phenomena, and leads to the nucleation of the first grain nuclei, mostly close to the initial grain boundaries where strain incompatibilities are stronger due to grain boundary shear - and also inside grains, particularly on grain fragmentation new boundaries (Fig.5). As a result, subboundary generation and disorientation are to be investigated in order to evaluate the nucleation rate.

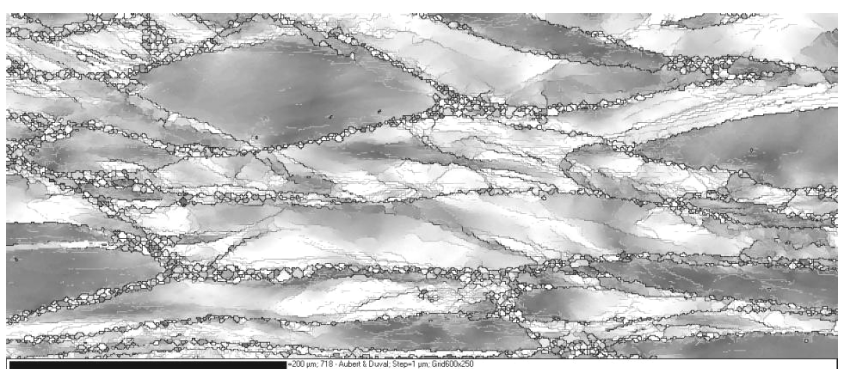

Figure 5. EBSD Map

$D_{0}=200 \mu \mathrm{m}-950^{\circ} \mathrm{C} 0.01 \mathrm{~s}^{-1} \varepsilon=1-$ Uniaxial compression Boundaries in light gray $\left(2^{\circ}\right)$ to black $\left(\geq 15^{\circ}\right)$

Subboundary disorientation kinetics. Subboundary formation involves recovery and GN dislocation rearrangement. As EBSD does not allow accurate measurement of disorientations less than $1^{\circ}$, the disorientation of newly generated subboundaries will be assumed to be $1^{\circ}$. Accumulating $\mathrm{GN}$ dislocations in subboundaries due to recovery causes their disorientation to increase. Specific disorientation distributions are established through these phenomena. When these distributions are drawn in logarithmic scales, they appear to be close to straight lines, as illustrated in figure 6 , indicating that disorientation distributions are close to power laws with negative exponents (Eq.1):

$$
\mathrm{f}(\theta)=\mathrm{k} \theta^{-\mathrm{m}}
$$

where $\mathrm{m}$ is a positive value, and $\mathrm{k}$ a normalization parameter. The value for $\mathrm{m}$ depends weakly on strain rate but strongly on temperature, and is about 1.5 at $900^{\circ} \mathrm{C}$, increasing up to about 3.5 4.0 at $1100^{\circ} \mathrm{C}$.

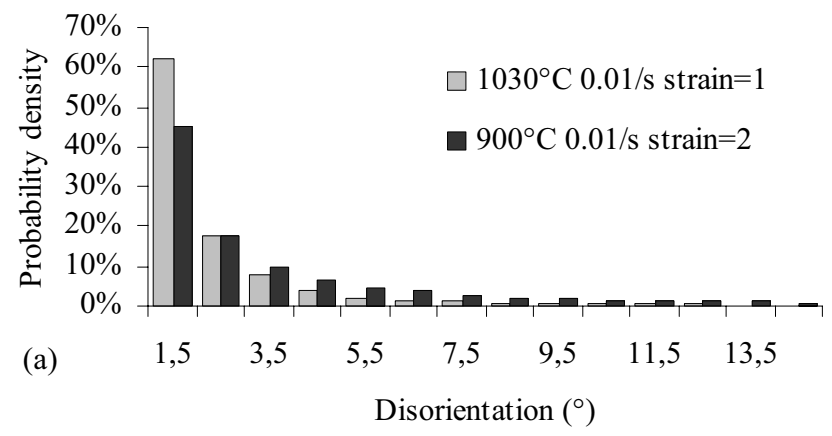

(b) Disorientation $\left(^{\circ}\right)$ (logarithmic scale)

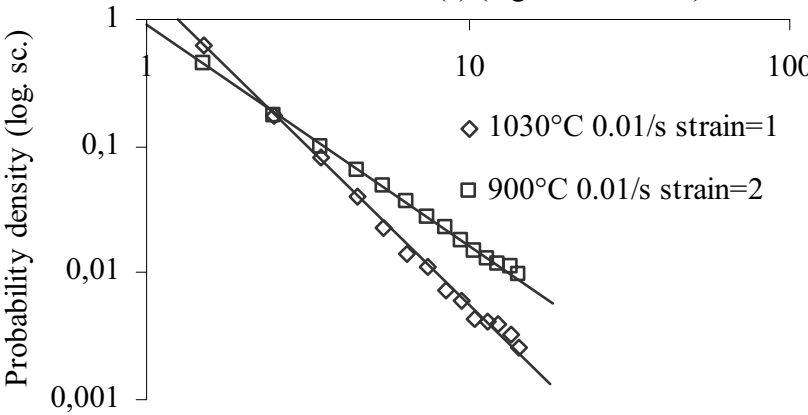

Figure 6. Measured subboundary disorientation distributions (a) represented in logarithmic scale (b) 
The slope of disorientation distributions increases with strain, revealing that subboundaries are progressively disoriented through deformation, filling higher disorientation ranges (Fig.7). After strains of about 0.5 , the slope - i.e. $\mathrm{m}$ - becomes stable, indicating the distributions reach a steady state, probably linked to an equilibrium between strain hardening and dynamic recovery, particularly inside strain heterogeneity affected zones, where high angle subboundaries appear first. Substructure is able to dissipate energy and accommodate deformation incompatibility between neighbor grains. However, high angle subboundary low probability values can surprise, as in the mean time they are observed as being responsible for the generation of large amounts of high angle boundaries. Actually, studying subboundary disorientation kinetics, thanks to these disorientation distributions, is helpful to remove this apparent contradiction.

The subboundary disorientation distribution tends to become stable at a value of $\mathrm{m}$ that will be noted $\mathrm{m}_{\mathrm{s}}$. Let's assume that any subboundary will be disoriented up to $15^{\circ}$ : flux conservation in subboundary population is necessary, which is expressed in equation 2:

$$
\mathrm{f}(\theta) \dot{\theta}=\mathrm{k} \theta^{-\mathrm{m}_{\mathrm{s}}} \dot{\theta}=\text { constant }
$$

Then the law of disorientation kinetics is given by equation 3 :

$$
\dot{\theta}(\theta)=\mathrm{c} \theta^{\mathrm{ms}}
$$

where $\mathrm{c}$ is a constant. As $\mathrm{m}_{\mathrm{s}}$ is positive, the more a subboundary is disoriented, the higher is its disorientation kinetics. This law underlines the connection of disorientation with strain heterogeneity. As it expresses average disorientation kinetics, equation 3 combines the disorientation kinetics with the probability for a given subboundary to be disoriented. Because low disorientation subboundaries appear anywhere in grains, their average disorientation kinetic is low. On the contrary, subboundaries that have reached high levels of disorientation are inevitably located in strain heterogeneity affected zones, so that their disorientation must increase, and at a rapid rate.

This formulation allows reproduction of disorientation distribution evolution through deformation. A comparison between measurements and calculated results is presented in figure 7.

Twin boundary evolution. Twin boundaries are disoriented due to strain because of activation of different slip systems in the crystals on their two sides. Thus initial twin boundaries are progressively transformed into ordinary mobile high angle boundaries through straining: twin boundary ratio decreases with strain at the beginning of deformation. But an increase is noted as recrystallization starts (Fig.8). In effect, twin boundaries are generated due to mobile boundary migration that takes place within recrystallized grains necklaces. These new twin boundaries are also transformed into ordinary high angle boundaries by continuing deformation, and thus contribute in establishing the steady state of dynamic recrystallization.

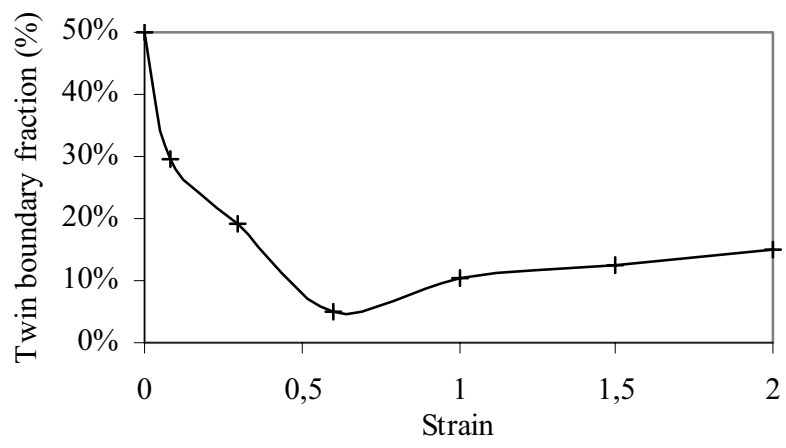

Figure 8 . Twin boundary fraction evolution with strain in torsion at $1030^{\circ} \mathrm{C} 0.01 \mathrm{~s}^{-1}$

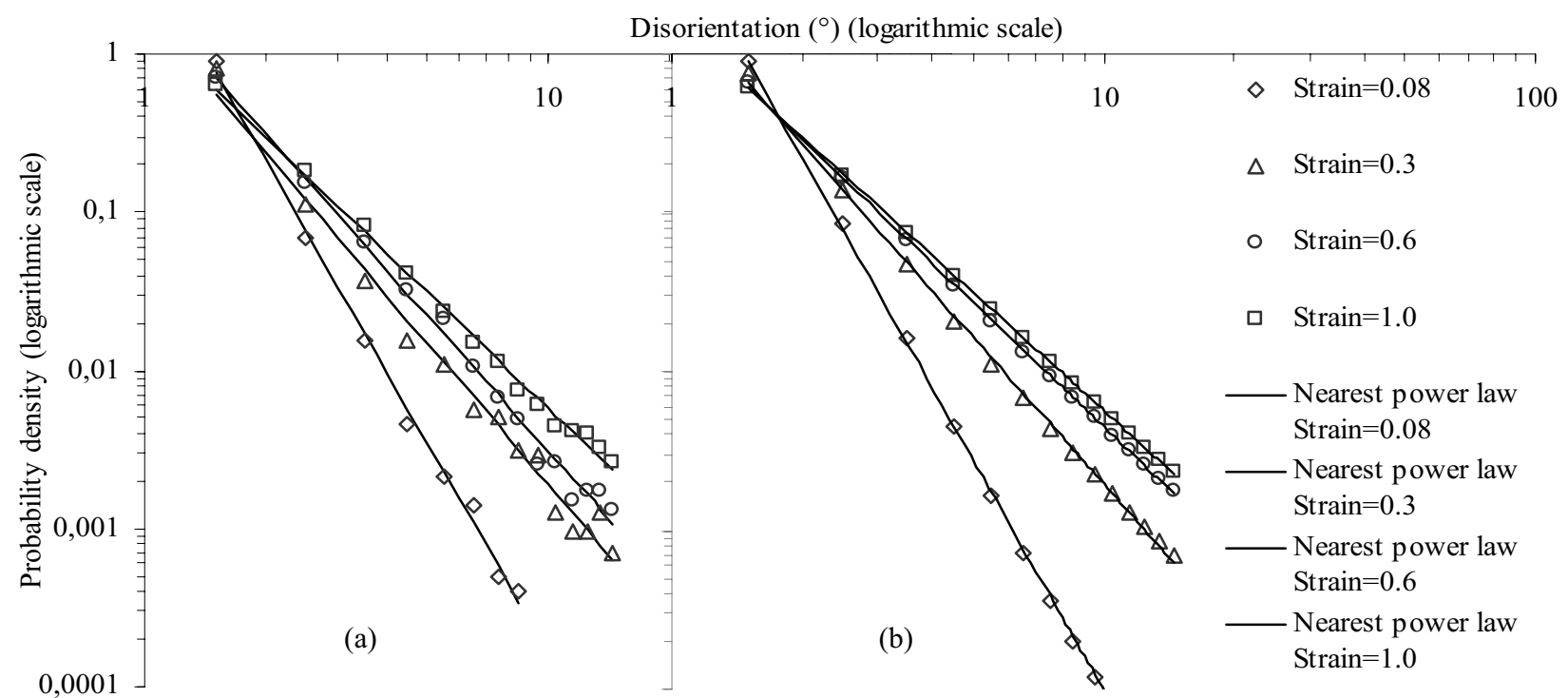

Figure 7. Measured (a) and calculated (b) subboundary disorientation distributions represented in logarithmic scales with their respective power law estimations, for several strains in torsion at $1030^{\circ} \mathrm{C}_{0.01 \mathrm{~s}^{-1}}$ 
In conclusion, disorientation phenomena govern the recrystallization behavior of alloy 718 by generating all the new mobile boundaries needed to eliminate stored energy (Fig.9).

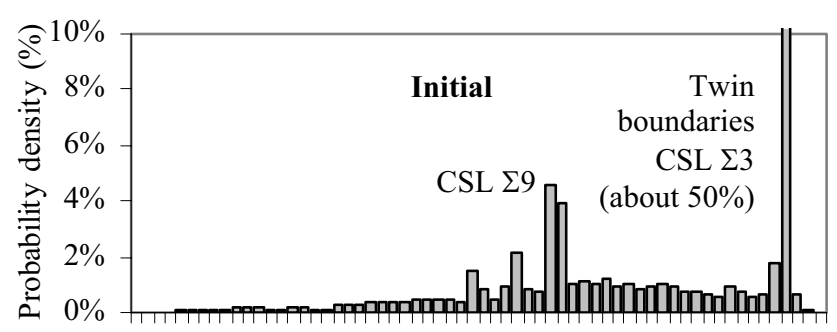

$\begin{array}{llllllllllll}1,5 & 7,5 & 13,5 & 19,5 & 25,5 & 31,5 & 37,5 & 43,5 & 49,5 & 55,5 & 61,5\end{array}$

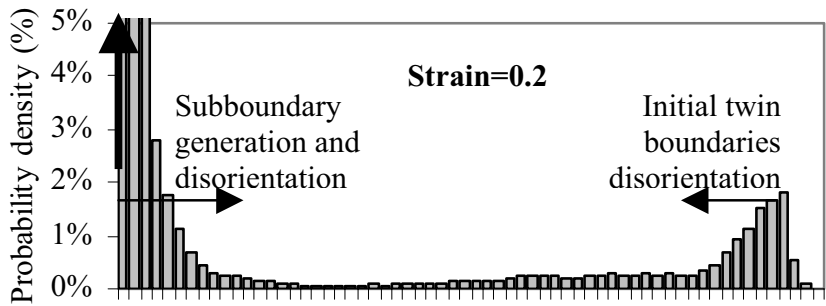

$\begin{array}{lllllllllll}1,5 & 7,5 & 13,5 & 19,5 & 25,5 & 31,5 & 37,5 & 43,5 & 49,5 & 55,5 & 61,5\end{array}$

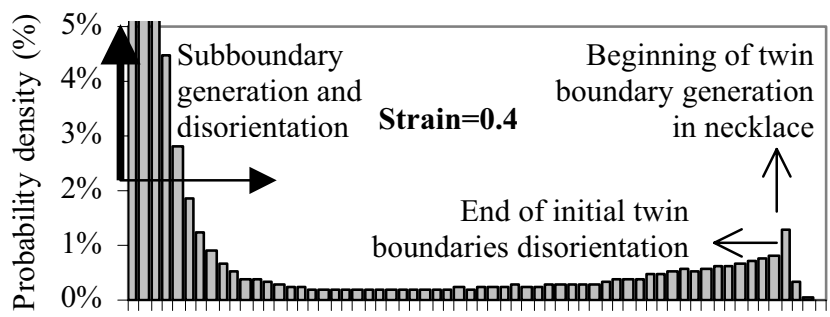

$\begin{array}{lllllllllll}1,5 & 7,5 & 13,5 & 19,5 & 25,5 & 31,5 & 37,5 & 43,5 & 49,5 & 55,5 & 61,5\end{array}$

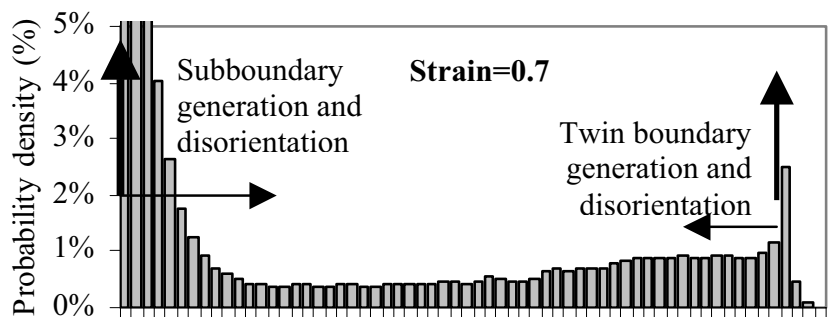

$\begin{array}{lllllllllll}1,5 & 7,5 & 13,5 & 19,5 & 25,5 & 31,5 & 37,5 & 43,5 & 49,5 & 55,5 & 61,5\end{array}$

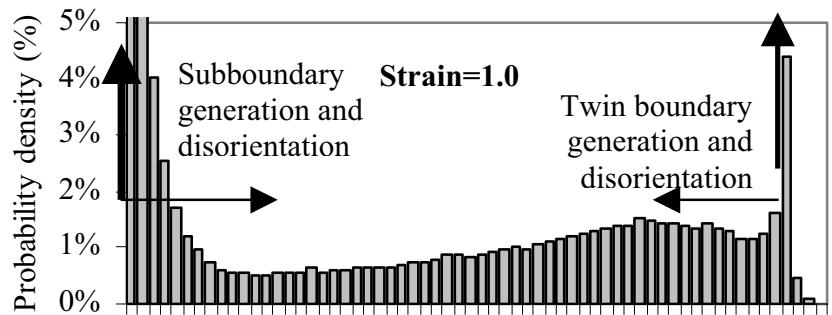

$\begin{array}{lllllllllll}1,5 & 7,5 & 13,5 & 19,5 & 25,5 & 31,5 & 37,5 & 43,5 & 49,5 & 55,5 & 61,5\end{array}$ Disorientation

Figure 9. a. Boundary disorientations distribution evolution with strain in uniaxial compression at $980^{\circ} \mathrm{C}^{0.01 \mathrm{~s}^{-1}}$
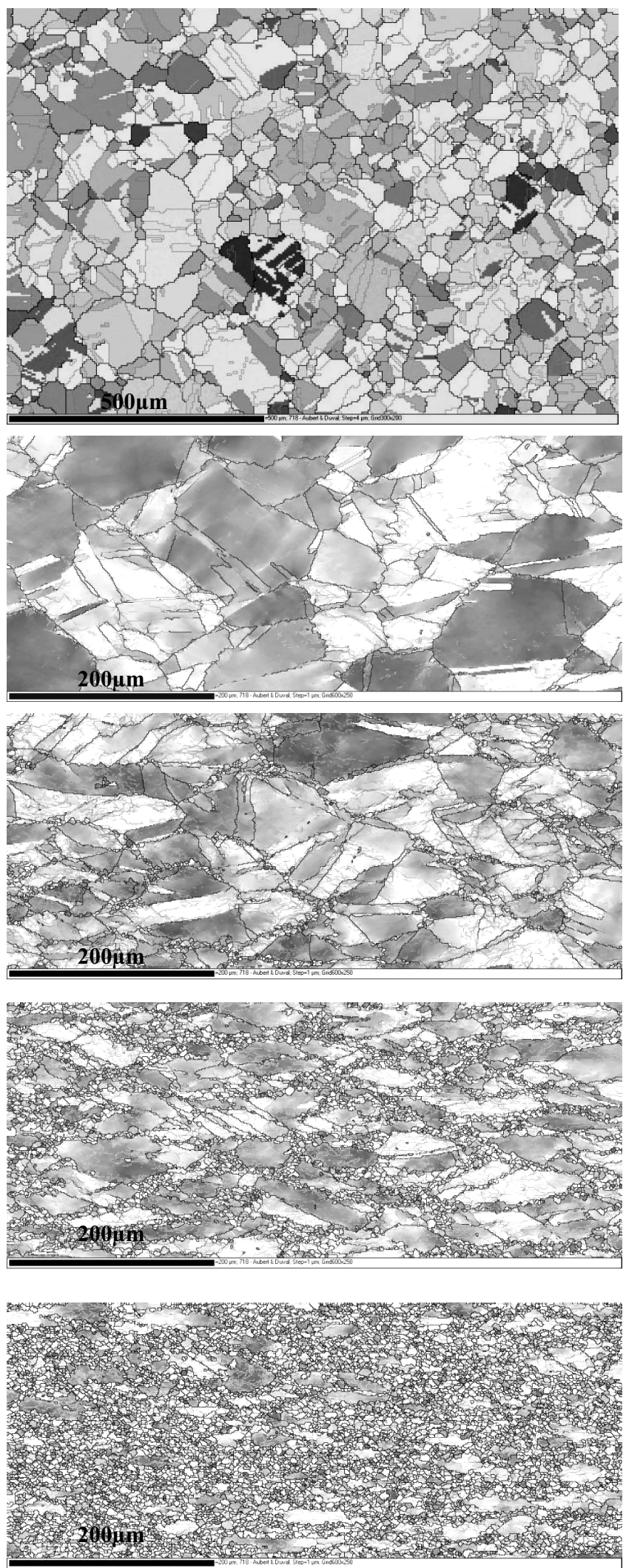

Figure 9. b. EBSD maps from which were obtained the disorientation distributions presented in a. 
After deformation, long enough holding times allow complete microstructure recrystallization in most cases. For initial microstructures containing large amounts of $\delta$ phase, metadynamic recrystallization is slowed down. Sometimes it can even be stopped before completion. When $\delta$ phase precipitates present acicular morphology, recrystallized zones cannot pass through precipitates, as illustrated in figure 10.

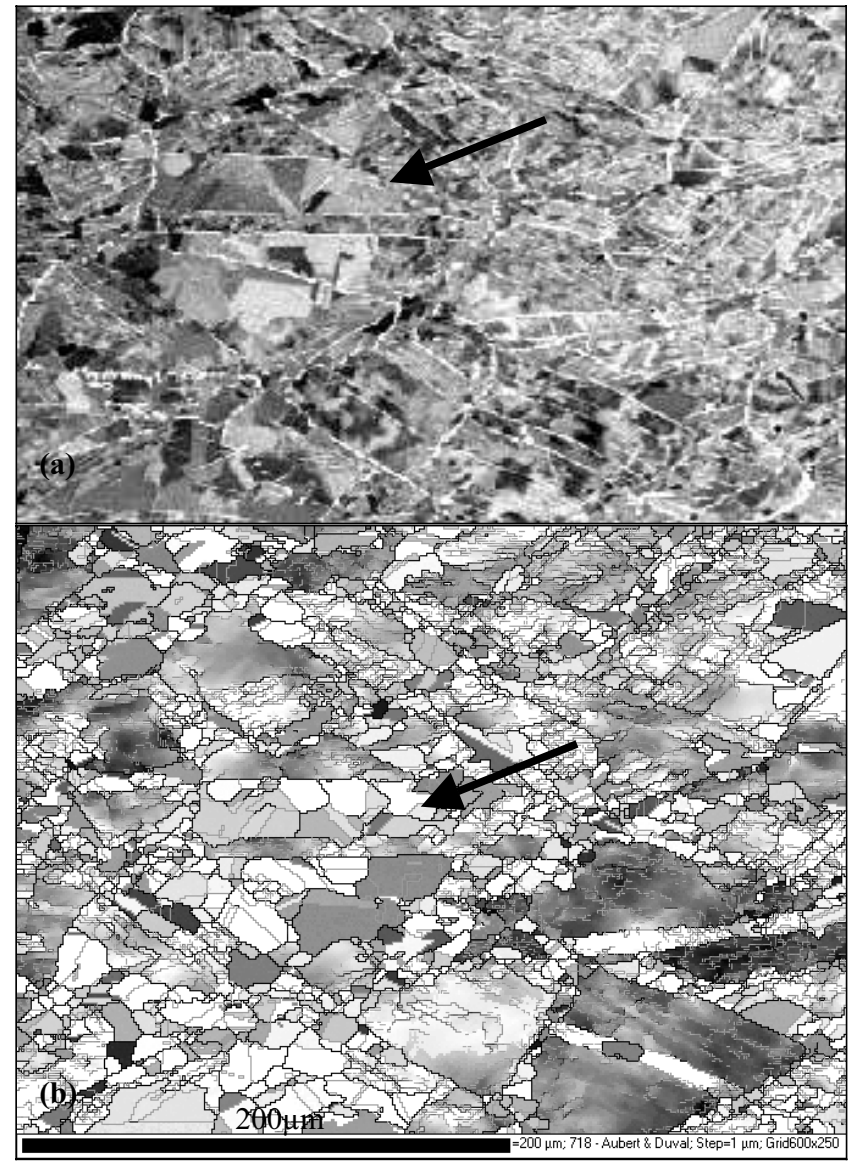

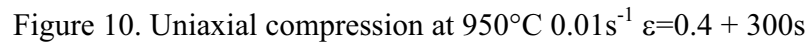
(a) Backscattered electrons image (chemical and crystallographic contrasts) and (b) corresponding EBSD map

Arrows indicate a recrystallized zone between two $\delta$ phase plate precipitates, which are impeding recrystallized grain boundaries from migrating outside

After this overview of alloy 718 experimentally observed microstructural evolutions, we can progress with development of models for them. Two methods will be presented: Avrami-based modeling and mechanism-based modeling.

\section{Empirical modeling}

This is the most common modeling, based on the use of Avrami laws (JMAK). It is widely used for industrial purposes $[1,3]$. Here, refinements have been added so that microstructure prediction is possible not only for one but also several deformation sequences. The basic model equations are the following ones.
Dynamic recrystallization kinetics are expressed in equations 4 and 5 as follows:

$$
\begin{gathered}
\mathrm{X}_{\mathrm{dyn}}=1-\exp \left(-\ln 2\left(\frac{\varepsilon}{\varepsilon_{0.5}}\right)^{\mathrm{n}_{\mathrm{d}}}\right) \\
\varepsilon_{0.5}=\mathrm{k}_{\mathrm{d}} \dot{\varepsilon}^{\mathrm{m}} \exp \left(\frac{\mathrm{Q}_{\mathrm{d}}}{\mathrm{RT}}\right) \mathrm{d}_{0}^{\mathrm{p}}
\end{gathered}
$$

where $k_{d}, n_{d}, m, Q_{d}$ and $p$ are constants, $d_{o}$ is the initial grain size, $\dot{\varepsilon}$ is the strain rate, and $\mathrm{T}$ the absolute temperature. Continuity with metadynamic recrystallization is given by equations 6 and 7 :

$$
\begin{gathered}
\mathrm{X}_{\text {mdyn }}=\mathrm{X}_{\text {dyn }}+\left(1-\mathrm{X}_{\text {dyn }}\right) \cdot\left(1-\exp \left(-\ln 2\left(\frac{\mathrm{t}}{\mathrm{t}_{0.5}}\right)^{\mathrm{n}_{\mathrm{md}}}\right)\right) \\
\mathrm{t}_{0.5}=\mathrm{k}_{\mathrm{md}} \varepsilon^{\mathrm{a}} \dot{\varepsilon}^{\mathrm{q}} \exp \left(\frac{\mathrm{Q}_{\mathrm{md}}}{\mathrm{RT}}\right) \mathrm{d}_{0}^{\mathrm{r}}
\end{gathered}
$$

where $\mathrm{k}_{\mathrm{md}}, \mathrm{n}_{\mathrm{md}}$, a, $\mathrm{q}$ and $\mathrm{r}$ are constants, $\dot{\varepsilon}$ is the previous strain rate, and $d_{o}$ is the initial grain size.

Dynamic grain sizes are calculated according to equations 8 and 9:

$$
\begin{gathered}
\mathrm{d}_{\mathrm{dyns}}=\mathrm{k}_{\mathrm{ds}} \dot{\varepsilon}^{\mathrm{m}_{\mathrm{d}}} \exp \left(-\frac{\mathrm{Q}_{\mathrm{ds}}}{\mathrm{RT}}\right) \\
\mathrm{d}_{\text {dyn }}(\varepsilon)=\mathrm{d}_{\text {dyns }} \mathrm{X}_{\text {dyn }}^{\alpha}
\end{gathered}
$$

where $d_{\text {dyns }}$ is the recrystallized grain size when the dynamic recrystallization steady state is reached and $d_{d y n}$ is the recrystallized grain size when recrystallization is in progress. $\mathrm{k}_{\mathrm{ds}}$, $\mathrm{m}_{\mathrm{d}}, \mathrm{Q}_{\mathrm{ds}}$, and $\alpha$ are constants. As before, continuity with subsequent metadynamic regime is provided, using equation 10 :

$$
\mathrm{d}_{\text {mdyn }}=\left(\mathrm{d}_{\text {dyn }}(\varepsilon)^{1 / \beta}+\mathrm{k}_{\text {mds }} \exp \left(-\frac{\mathrm{Q}_{\mathrm{mds}}}{\mathrm{RT}}\right) \cdot \mathrm{t}\right)^{\beta}
$$

where $t$ is holding time, $k_{m d s}, Q_{m d s}$ and $\beta$ are constants. It can be seen here that $d_{\text {mdyn }}$ is given by an equation quite different from commonly accepted ones. It shows that most of the recrystallized grains metadynamic evolution in the necklace structure is due to grain boundary surface tension, and depends slightly on the predeformation that was made. Initial grain size evolutions is written through geometric considerations as expressed in equation 11 :

$$
\mathrm{d}_{\text {strained }}=\mathrm{d}_{0}(1-\mathrm{X})^{1 / 3}
$$

where $\mathrm{X}$ can be $\mathrm{X}_{\mathrm{dyn}}$ or $\mathrm{X}_{\mathrm{mdyn}}$. 
These equations allow predicting microstructural evolutions occurring during only one deformation step. But actual industrial processes involve several consecutive deformations. Refinements are to be defined to permit this. Equations 4 to 11 produce, after each deformation and subsequent holding time, two grain families: the recrystallized grains and the remaining ones. For any consecutive deformation, these equations are applied to each of these two families, which leads to have four families of grains. The two families given by recrystallized grains are mixed with the recrystallized grains coming from strained grains into a single family of recrystallized grains. These three families are likely to have similar grain sizes and stored energy levels. The remaining initial grains are kept as one family. The cumulative result is made of two grain families: 1) the remnants of initial strained grains, and 2) those that have recrystallized at least once. The calculation procedure is drawn in the following diagram (Fig.11):

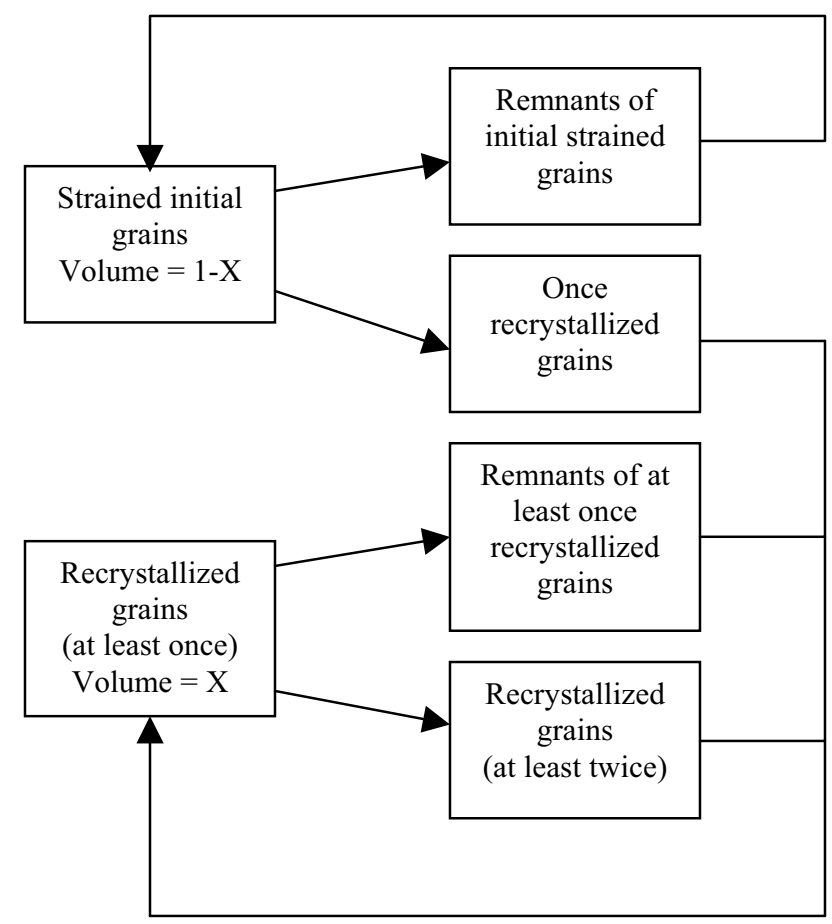

Figure 11. Grain families mixing procedure used after any deformation step ( $\mathrm{X}$ is recrystallized fraction)

Using this procedure still does not give satisfactory results for multiple consecutive deformations. When the number of steps increases, a recrystallization delay appears. The reason for this phenomenon lies in the fact that at each step, the strain of deformed grains is assumed to be restored to zero, whereas actually, a part of the previous deformation is still stored into them. Consequently, refinement of the procedure was required.

The actual deformation applied in equations for the remnants of initial grains is given by equation 12 :

$$
\varepsilon_{\mathrm{i}}=\varepsilon+\lambda \varepsilon_{\mathrm{i}-1}
$$

where $\varepsilon_{\mathrm{i}}$ is the deformation used in equations 4 to 11 for strained initial grains, $\varepsilon_{\mathrm{i}-1}$ is the one that was used for the prior one (it is originally initialized to zero), and $\lambda$ is a temperature dependent parameter taken between 0 and 1 . The complementary part of $\lambda$ represents the recovery of these grains during inter-pass times.

This model was implemented into the finite element software Forge $3 \circledR$ to calculate microstructural evolutions of alloy 718 forged into the shape of an octagon bar by rotary forging. Results are presented in figure 12 below:
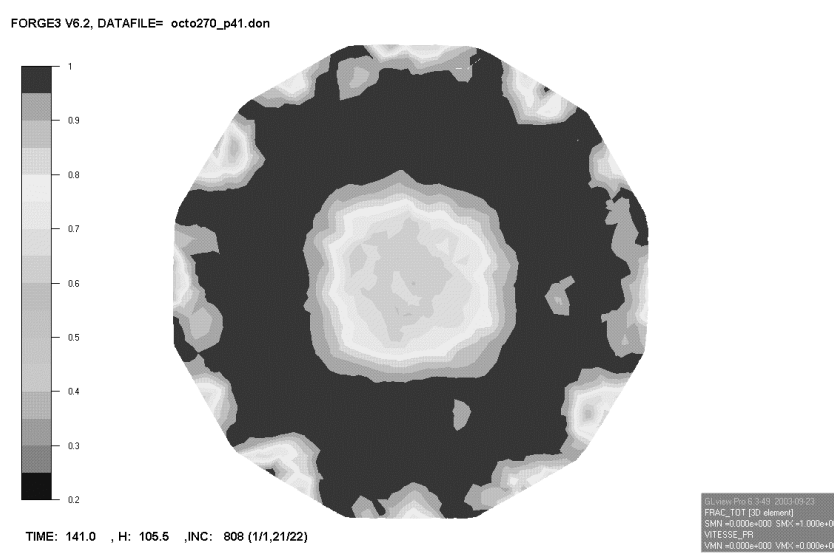

Figure 12a. Recrystallized fraction after rotary forging on a $270 \mathrm{~mm}$ octagon bar
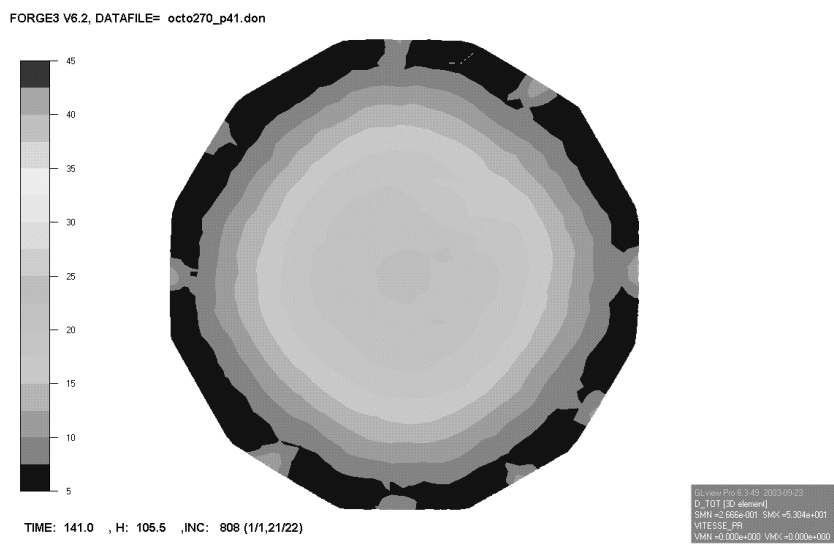

Figure 12b. Recrystallized grain size after rotary forging on a $270 \mathrm{~mm}$ octagon bar

This model is in good agreement with experimental data as long as it is applied to tests for which the initial microstructure did not contain excessive $\delta$ phase. It is not possible to solve results from any kind of initial microstructure in a single phenomenological model, since $\delta$ phase precipitates strongly retard metadynamic recrystallization. Thus this model is to be used when thermomechanical processing occurs at high enough temperatures (typically above the $\delta$ solvus).

A mechanism-based model is required to take account of the $\delta$ phase precipitates effects. A method is proposed into the next part. 


\section{Mechanism-based modeling}

\section{Microstructure mathematical description}

To represent the mechanisms that were described in the first part of this paper, it is necessary to describe microstructures in a suitable way, at mesoscale level. We consider microstructures as made of two types of grains: the initial ones and the recrystallized ones. Initial grains are given a 0 index, and a 1 index is used for the recrystallized ones. Each of these two families is described through a "mesostructure unit" or MSU. Actually, the model can be generalized to more than two MSU, if one wants to follow more than one type of recrystallized grains, as for instance recrystallized grains that appeared during previous thermomechanical processing steps. For simplicity, the model will be presented for only two MSU.

MSU are designed as a set of variables that are, for i index grains:

- $\quad n_{i}$ grain density in the volume

- $\quad D_{i}$ grain diameter in the volume

- $\quad \rho_{\mathrm{i}}$ free dislocation density

- $\mathrm{Ssb}_{\mathrm{ik}}$ with $1 \leq \mathrm{k} \leq 14$, surface densities of subboundaries for each disorientation $\theta_{\mathrm{k}}=\mathrm{k}+0.5$

- $\quad$ Stb $_{\text {ik }}$ with $0 \leq k \leq 4$, surface densities of twin boundaries for each disorientation $\theta_{\mathrm{k}}=59.5-\mathrm{k}$

Additional variables are defined, determined from the main ones at any time:

- $\quad \mathrm{Vg}_{\mathrm{i}}$ grain volume

- $\quad \mathrm{V}_{\mathrm{i}} \mathrm{MSU}$ volume

- $\quad$ Sgi grain surface

- $\quad \mathrm{Sgb}_{\mathrm{i}}$ grain boundary surface density

- $\quad \mathrm{Ssb}_{\mathrm{i}}$ subboundary surface density

- $\quad$ Stb $_{\mathrm{i}}$ twin boundary surface density

- $\quad \rho s b_{i}$ density of dislocations stored in subboundaries

Additional variable expressions are given in equations 13 to 19:

$$
\begin{gathered}
\mathrm{Vg}_{\mathrm{i}}=\frac{\pi}{6} \mathrm{D}_{\mathrm{i}}^{3} \\
\mathrm{~V}_{\mathrm{i}}=\mathrm{n}_{\mathrm{i}} \mathrm{Vg}_{\mathrm{i}} \\
\mathrm{Sg}_{\mathrm{i}}=\pi \mathrm{D}^{2} \\
\mathrm{Sgb}_{\mathrm{i}}=\frac{\mathrm{n}_{\mathrm{i}}}{2} \frac{\mathrm{Sg}_{\mathrm{i}}}{\mathrm{V}_{\mathrm{i}}}=\frac{3}{\mathrm{D}_{\mathrm{i}}} \\
\mathrm{Ssb}_{\mathrm{i}}=\sum_{\mathrm{k}=1}^{14} \mathrm{Ssb}_{\mathrm{ik}} \\
\mathrm{Stb}_{\mathrm{i}}=\sum_{\mathrm{k}=0}^{4} \mathrm{Stb}_{\mathrm{ik}} \\
\rho s \mathrm{~b}=\sum_{\mathrm{k}=1}^{14} \mathrm{Ssb}_{\mathrm{ik}} \frac{\mathrm{N} \theta_{\mathrm{k}}}{\mathrm{b}}
\end{gathered}
$$

This last equation is based on the assumption [2] that the disorientation of a subboundary is connected to the dislocation density per subboundary surface unit $\rho_{\mathrm{s}}$ as follows:

$$
\theta=b \frac{\rho_{\mathrm{s}}}{\mathrm{N}}
$$

where $\mathrm{N}$, about 3 , is the number of dislocation families stored in the considered subboundary. $\mathrm{b}$ is the Burgers vector modulus.
The modeling of $\delta$ phase precipitation will not be detailed in this paper. However, a precipitation model, derived from the one designed during another study [4], is coupled with this model. Thus $\mathrm{X}_{\mathrm{p}}$ and $\mathrm{D}_{\mathrm{p}}$, which are respectively the precipitate fraction and the precipitate size, are also used, so as to represent $\delta$ phase precipitates.

\section{Grain interactions}

Grain interactions involve grain boundary surfaces. The probability that a given grain is in contact with a grain of MSU i is defined as:

$$
\mathrm{q}_{\mathrm{i}}=\frac{\mathrm{Sgb}_{\mathrm{i}}}{\mathrm{Sgb}_{0}+\mathrm{Sgb}_{1}}
$$

so that the grain boundary surface of MSU $\mathrm{j}$ which is in contact with grains of MSU $i$ is given by:

$$
\operatorname{Sgb}_{i-j}=\operatorname{Sgb}_{j} q_{i}=\frac{\operatorname{Sgb}_{j} \operatorname{Sgb}_{i}}{\operatorname{Sgb}_{0}+\operatorname{Sgb}_{1}}=\operatorname{Sgb}_{i} q_{j}=\operatorname{Sgb}_{j-i}
$$

External grain interactions [5]. External interactions are between the two different MSU. MSU i grain volume change is given by:

$$
\begin{gathered}
\dot{V}_{i}=\operatorname{Sgb}_{i-j} M P_{i-j} \\
P_{i-j}=\frac{G b^{2}}{2}\left(\rho_{j}-\rho_{i}+k_{s b}\left(\rho s b_{j}-\rho s b_{i}\right)\right)-\frac{\gamma}{2 D_{i}} \pm P_{z} \text { if } D i<D j \\
P_{i-j}=\frac{G b^{2}}{2}\left(\rho_{j}-\rho_{i}+k_{s b}\left(\rho s b_{j}-\rho s b_{i}\right)\right)+\frac{\gamma}{2 D_{j}} \pm P_{z} \text { if } D j<D i
\end{gathered}
$$

where Pi-j is the driving force for moving boundaries that are $\mathrm{i} / \mathrm{j}$ interfaces. $\mathrm{M}$ is grain boundary mobility, $\mathrm{G}$ is Coulomb's modulus, $\gamma$ is grain boundary surface tension, ksb is a parameter set between 0 and 1 , and $\mathrm{Pz}$ is the Zener pinning parameter due to $\delta$ phase. It is written as follows:

$$
\mathrm{P}_{\mathrm{z}}=\mathrm{k}_{\mathrm{z}} \gamma \frac{\mathrm{X}_{\mathrm{p}}}{\mathrm{D}_{\mathrm{p}}}
$$

where $\mathrm{kz}$ is a constant. It is to be noted that thanks to the symmetry observed in equations 22 to 25 , the volume variation of i grains, when they interact with $\mathrm{j}$ grains, is exactly the opposite of the one of $\mathrm{j}$ grains in interaction with $\mathrm{i}$ grains. Total volume conservation is ensured.

Internal grain interactions. They are between grains of the same MSU, thus they induce no volume change of the considered MSU. Driving force is given by:

$$
\mathrm{P}_{\mathrm{i}-\mathrm{i}}=\frac{\gamma}{2 \mathrm{D}_{\mathrm{i}}}-\mathrm{P}_{\mathrm{z}}
$$

This driving force induces a change in the grain boundary surface [2] as written in equation 27:

$$
\dot{\mathrm{S} g b}_{\mathrm{i}}=-\mathrm{Sgb}_{\mathrm{i}} \mathrm{Sgb}_{\mathrm{i}-\mathrm{i}} \mathrm{MP}_{\mathrm{i}-\mathrm{i}}
$$


This grain boundary surface decrease leads to increase the grain diameter:

$$
\dot{\mathrm{D}}_{\mathrm{i}}=-3 \frac{\dot{\mathrm{S} g b_{\mathrm{i}}}}{\mathrm{Sgb}_{\mathrm{i}}^{2}}
$$

\section{$\underline{\text { Static grain growth }}$}

Considering that only one MSU has grains, and that no deformation was made, it is possible to readily deal with static grain growth. Equation 28 can be written as equation 29:

$$
\dot{\mathrm{D}}_{\mathrm{i}}=3 \mathrm{MP}_{\mathrm{i}-\mathrm{i}}=3 \mathrm{M}\left(\frac{\gamma}{2 \mathrm{D}_{\mathrm{i}}}-\mathrm{P}_{\mathrm{z}}\right)
$$

where $M$ is the grain boundary mobility. At high enough temperatures, $\mathrm{Pz}$ is zero as all niobium is in solution. Integration of equation 29 leads to an equation like 30 :

$$
\mathrm{D}^{\mathrm{n}}-\mathrm{D}_{\mathrm{ini}}^{\mathrm{n}}=\mathrm{kt}
$$

with $n=2$ for a constant $M$, or $n=3$ if $M$ is assumed to depend linearly on the driving force. Actually, measures show that $\mathrm{n}$ is more likely to be about 3.5. As coarse grain growth kinetics are slowed down when boundaries meet carbides, we can assume that before they meet them, $\mathrm{n}$ is about 3 , which implies that the grain boundary mobility depends linearly on the driving force:

$$
\mathrm{M}=\mathrm{M}_{0} \frac{\mathrm{P}}{\mathrm{P}_{0}}
$$

where Mo depends on temperature, which is written using an Arrhenius law, Po is the driving force for static growth of a $1 \mu \mathrm{m}$ grain, and $\mathrm{P}$ is the driving force, which is $\mathrm{Pi}-\mathrm{i}$ here. Application of these laws to high temperature grain growth is shown in figure 13.

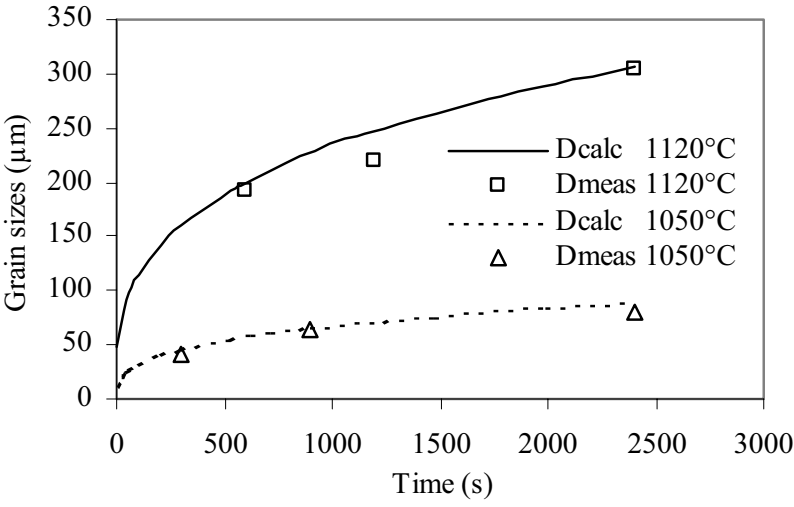

Figure 13. Grain growth without $\delta$ phase

Comparison between measured and calculated grain sizes

Using these expressions at lower temperatures helps to estimate the Zener pinning coefficient kz. It allows predicting the grain size evolution during static grain growth even when niobium segregation has strong influence, as illustrated in figure 14.

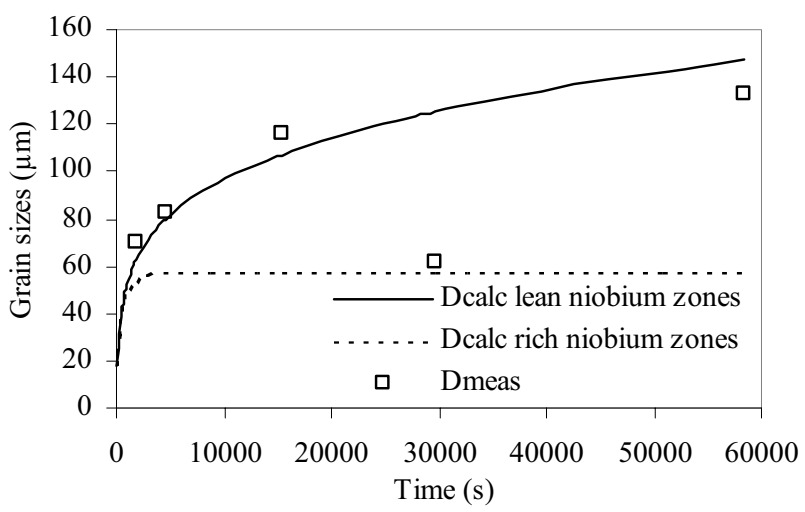

Figure 14. Grain growth at a temperature lower than the $\delta$ phase solvus; Comparison between measured [4] and calculated grain sizes, depending on the local niobium content

\section{Dynamic and metadynamic evolutions}

Dislocation generation and recovery are calculated through the Laasraoui-Jonas model. Free dislocations have a weak influence on recrystallization kinetics, whereas subboundary generation and disorientation define most of them. Subboundary generation depends weakly on strain rate but strongly on temperature and grain size. Its diminution for coarse grains reveals that most of strain heterogeneity is located near grain boundaries. Subboundary disorientation is calculated as presented previously in this paper.

First, the recrystallization model was solved for initial microstructures without $\delta$ phase. But when this model was applied to initial microstructures with $\delta$ phase, using the kz parameter that was identified for static grain growth, and with the static precipitation model, it appeared that metadynamic recrystallization kinetics were underestimated, showing that the influence of $\delta$ phase was overestimated. As $\mathrm{kz}$ has no reason to change from the static regime to the dynamic one, it was concluded that $\delta$ phase itself has different evolutions depending on the amount of energy stored thanks to straining. In particular, as the influence of $\delta$ phase was overestimated, one can conclude that straining leads to a very quick dynamic dissolution of $\delta$ phase. This phenomenon was clearly observed on samples [4]. However, $\delta$ phase precipitates do not disappear completely. Thus, during deformation, $\delta$ phase Zener pinning effect is between the strong level that would be observed for $\delta$ phase static behavior and the vanishing one that would be observed for a complete dissolution. Solving the model to take into account different static and dynamic $\delta$ phase precipitate evolutions is currently being done: final numerical optimization is still to be calculated. It already shows that dynamic $\delta$ phase dissolution depends not only on temperature and stored energy but also on precipitate morphology.

Present results are shown in figures $16 \mathrm{a}$ and $\mathrm{b}$, and show the dispersion is still large. The database contains the experimental values obtained from the more than 500 EBSD maps of this study along with measurements from other studies. The comparison of measured and calculated values is made on more than 600 recrystallized fractions and more than 900 recrystallized grain sizes. They are given for broad range of experimental conditions: 
torsion or uniaxial compression, with strain rates from $0.001 \mathrm{~s}^{-1}$ to $10 \mathrm{~s}^{-1}$, or temperatures in the range $900^{\circ} \mathrm{C}-1120^{\circ} \mathrm{C}$. Initial grain sizes are between $12 \mu \mathrm{m}$ and $200 \mu \mathrm{m}$, holding times vary from 0 to 16 hours. Initial microstructures can be without $\delta$ phase precipitates or contain precipitates of any morphology from globular to acicular.

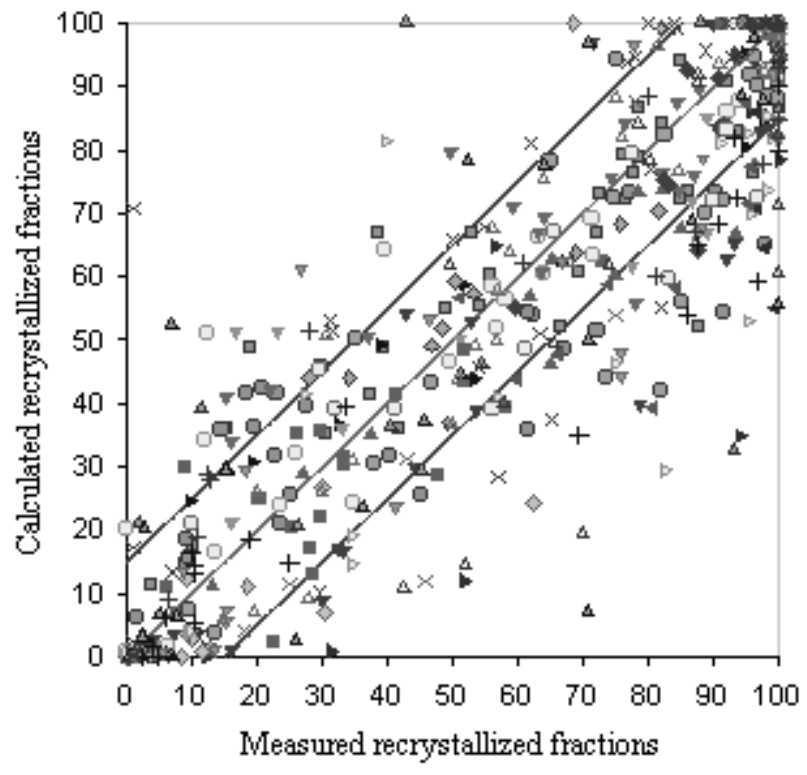

Figure 16-a. Calculated vs. measured recrystallized fractions

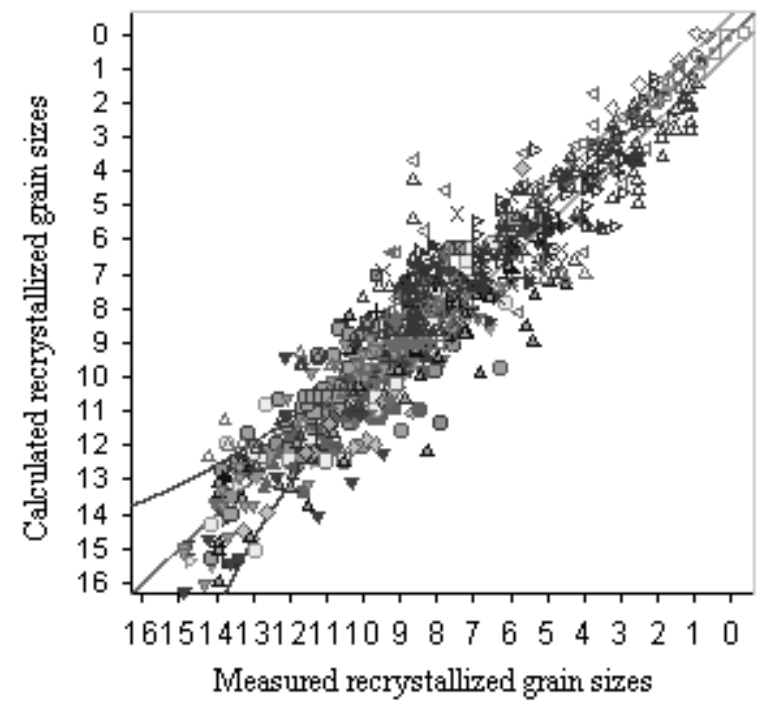

Figure 16-b. Calculated vs. measured recrystallized grain sizes

\section{Finite element application}

Post-processing software was developed to integrate the model on FEM results given by Forge $2 \AA$. In particular, it allows treating correctly the transport of variables when re-meshing occurs, which is really necessary for mechanism-based models. The die forging and subsequent cooling of an aircraft engine disc was calculated. Obtained results are shown and compared to measurements in figure 17.

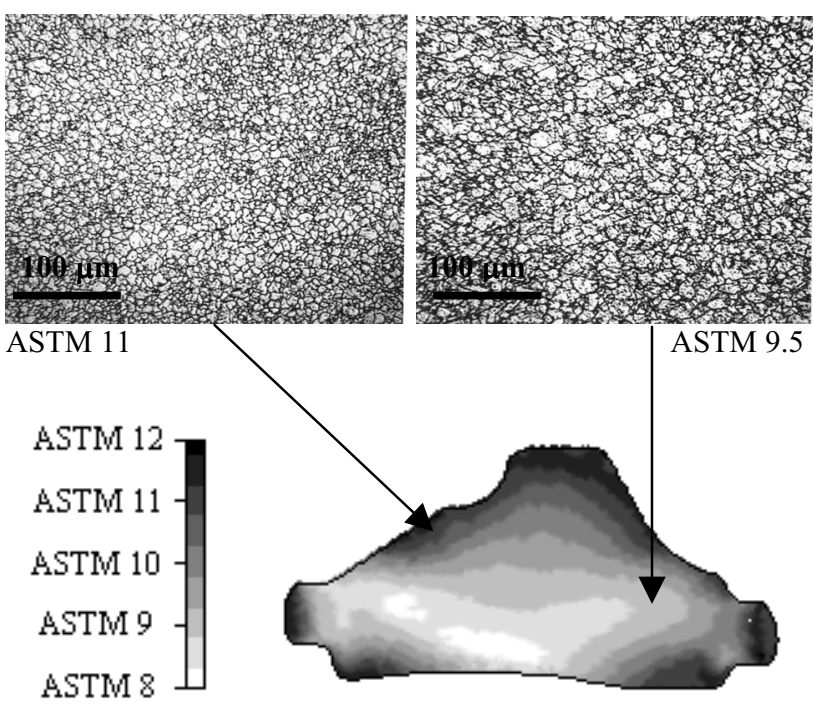

Figure 17. Calculated grain size map of a die forged aircraft engine disc; comparison with measurements

This mechanism-based model is already in good agreement with measured values, even if it tends to overestimate recrystallized grain sizes by 0.5 to 1 ASTM. An error is certainly done when estimating the $\delta$ phase re-precipitation kinetics after the end of deformation. When metadynamic recrystallization eliminates the energy that was stored during deformation, re-precipitation kinetics seem to be slightly higher than the purely static one, so that $\delta$ phase precipitates control more grain boundary migration than predicted. Numerical optimisation may reduce this kind of error.

\section{Conclusions}

The microstructural evolutions of alloy 718 were investigated using the EBSD technique: it was shown that disorientation phenomena govern the recrystallization behavior of this alloy. An empirical model based on the Avrami law was solved for high temperatures. At lower temperatures, $\delta$ phase slows down recrystallization kinetics. A mechanism-based model was developed to deal with the coupling effects of recrystallization with $\delta$ phase precipitation.

\section{References}

1. G. Shen, J. Rollins, and D. Furrer, "Microstructure Modeling of Forged Waspaloy Discs", Superalloys 1996, 613-620

2. S. Gourdet, and F. Montheillet, "A model of continuous dynamic recrystallization", Acta Mater. 51, 2003, 2685-2699

3. B. Antolovitch, and M. Evans, "Predicting Grain Size Evolution of UDIMET ${ }^{\circledR}$ alloy 718 During The "Cogging" Process Through the Use of Numerical Analysis", Superalloys 2000, 39-47 4. S. Coste, "Détermination des Lois d'Evolution Microstructurale de l'Alliage 718 lors du Matriçage", Thèse de Doctorat, Institut National Polytechnique de Toulouse, 2003

5. F. Montheillet, "Modeling the Steady State Regime of Discontinuous Dynamic Recrystallization", Proc. of the $4^{\text {th }}$ Int. Conf. on Recrystallization and Related Phenomena, 1999, 651658 